\title{
O MENINO NA SOMBRA DA MANGUEIRA: RAÍZES E FRUTOS DA OBRA FREIRIANA
}

\section{THE CHILD UNDER THE SHADE OF THE MANGO TREE: ROOTS AND FRUITS OF FREIRE'S WORK}

\author{
Mariateresa Muraca - Università di Verona \\ Paolo Vittoria - Universita degli Studi di Napoli Federico II
}

\begin{abstract}
RESUMO
O artigo é articulado em quatro sessões e percorre com estilo narrativo a trajetória de vida, teórica e política de Paulo Freire. A primeira parte debruça no percurso de criação do método de conscientização-alfabetização, explorando suas raízes existenciais e sociais e seus impactos contraditórios no Brasil e no mundo. A segunda sessão analisa as reinvenções da perspectiva freiriana à luz do encontro com outros contextos e intelectuais, detendo-se especialmente na contribuição de Freire ao processo de descolonização das ex-colônias portuguesas na África. A terceira sessão foca em alguns aspectos fundantes da perspectiva freiriana, como a centralidade do diálogo, a elaboração da teoria a partir de uma reflexão crítica sobre a prática, a reciprocidade do processo de aprendizagem entre educador e educando. Finalmente o artigo considera alguns dos principais desafios da atualidade, argumentado o papel dos movimentos sociais como reinventores da pedagogia freiriana.
\end{abstract}

Palavras-chave: Paulo Freire. educação crítica. alfabetização-conscientização. práxis decolonial. movimentos sociais.

\begin{abstract}
The article is organized ded into four sections and covers Paulo Freire's existencial, theoretical and political trajectory in a narrative style. The first part focuses on the path of creating the literacy-consciousness method, exploring its existential and social roots and its contradictory impacts in Brazil and in the world. The second session analyzes the reinventions of the Freirian perspective in the light of the encounter with other contexts and intellectuals, by stressing especially Freire's contribution to the process of decolonization of the former Portuguese colonies in Africa. The third session focuses on some fundamental aspects of Freire's perspective, such as the centrality of dialogue, the elaboration of theory from a critical reflection on practice, the
\end{abstract}


reciprocity of the process of learning between teacher and student. Finally, the article considers some of the main current challenges, arguing the role of social movements as reinventers of Freire's pedagogy.

Key-words: Paulo Freire. critical education. literacy-consciousness. decolonial práxis. social movements.

\title{
INTRODUÇÃO
}

\begin{abstract}
... As árvores sempre me atraíram. As frondes arredondadas, a variedade do seu verde, a sombra aconchegante, o cheiro das flores, os frutos, a ondulação dos galhos, mais intensa ou menos intensa em função de sua resistência ao vento. As boas-vindas que suas sombras sempre dão a quem a elas chega, inclusive aos passarinhos multicores e cantadores. Aos bichos, pacatos ou não, que nelas repousam. Nascido em Recife, menino de uma geração que cresceu em quintais, em íntima relação com árvores, minha memória não poderia deixar de ser repleta de experiências de sombra. Marcada por um gosto especial pelas sombras, que as gentes nascidas em trópicos cedo incorporam e dele falam como se tivessem nascido com ele. Não foram poucas as tardes em que estudava à sombra da jaqueira no quintal da nossa casa em Jaboatão. Sombra e luz, céu azul, horizonte fundo e amplo dizem de $\mathrm{mim}$. Sem eles apenas sobrevivo, menos do que existo. Minha biblioteca de adulto tem algo disso. Às vezes, é como se fosse a sombra da mangueira de minha infância (FREIRE, 1995 pp. 15-16).
\end{abstract}

Nessa narração, há muito da relação entre o educador Freire e o menino Paulo. As paisagens tropicais que desenham Recife, cidade do nordeste brasileiro onde Paulo nasceu em 1921, coloridas pelas árvores de fruta e pelo azul intenso de seu céu, a atmosfera do Recife nos evocam elementos vitais de infância de Paulo. Recife, onde a pobreza, a miséria, mas também a criatividade popular fazem parte da história de um país - o Brasil - fruto de séculos de depredação, de uma colonização violenta, que criou e reproduziu colonizações e violências internas, inclusive nas consciências das pessoas. Um sistema que até agora coloca uma pequena parte da população no privilégio dos "opressores" e a maioria na pobreza dos "oprimidos". Essa realidade era lida por Paulo desde a infância, à sombra daquela árvore. As injustiças eram sofridas com tristeza e desejo de resgate. Paulo Freire jamais teria escrito Pedagogia do Oprimido se aquele menino à sombra daquela árvore tivesse sido indiferente ao sofrimento e às iniquidades que o cercavam. 
Paulo Freire não teria escrito Pedagogia do Oprimido também se não fosse passado por Angicos, pequena localidade isolada do Sertão, estepe semidesértica da região norte do Brasil. As casas baixas, quase todas em tijolo, são simples, brancas, minutas... essenciais. A terra árida, a chuva parece nunca ter batido numa terra cujo tempo é muito lento e o trabalho muito árduo. No centro de Angicos uma igreja branca, de onde se destaca a torre. Paulo Freire usou essa torre para subir, mapear e organizar os círculos de cultura. Um pouco mais adiante, a rodoviária, outrora estação de trem (quando existiam), os correios, o cemitério, um antigo presídio, uma escola, um mercado e a imensa paisagem ensolarada que cerca Angicos. As ruas atravessadas por rostos marcados pelo sol e pelo trabalho dos campos numa atmosfera quase irreal, porque é lenta... rarefeita (VITTORIA, 2011).

\title{
Quebrar a distância entre o saber e a vida: o método de alfabetização- conscientização
}

Era o 1962, quando Paulo Freire lançou em Angicos uma campanha de alfabetização que marcou profundamente a história da educação no Brasil e no mundo.

Segundo o jornalista Carlos Lyra e seu livro As quarentas horas de Angicos (1996), na época, a percentagem de analfabetos era espantosa: em Angicos mais de 7 em cada 10 pessoas não sabiam ler ou escrever. Sobretudo no campo da alfabetização, os processos educativos se baseavam ainda numa memorização mecânica, desligada do contexto e longe da realidade. Como testemunha Marcos Guerra educador que colaborou com Paulo em Angicos:

\begin{abstract}
"uma das frases para aprender as sílabas iniciais que o Ministério da Educação utilizava na época era: "Ada deu o dedo ao urubu”. Estamos trabalhando com fonemas simples, mas certamente não fazem parte do vocabulário cotidiano. Ada não é um nome comum da região do Sertão, além disso ela daria o dedo a um papagaio e não a um urubu. Se déssemos o dedo para o urubu, o que o urubu faria com o nosso dedo? Ele provavelmente iria comer. Isso mostra a enorme distância entre o método tradicional e o dia a dia das pessoas. O princípio fundamental da prática de alfabetização de Paulo Freire era quebrar essa distância."1
\end{abstract}

\footnotetext{
${ }^{1}$ Vittoria, P. Angicos, uma experiencia política. Entrevista com Marcos Guerra https://www.youtube.com/watch?v=Y_xt6ZxW7EM\&t=1743s
} 
A revolução educativa provocada por Paulo Freire começou antes mesmo de entrar no processo de alfabetização. Nos círculos de cultura havia um diálogo sobre desenhos que expressavam situações existenciais. Aos poucos as pessoas foram sendo levadas a compreender que se existe um mundo que é dado, e são as coisas da natureza, outro mundo é criado sobre ele, obra da intervenção humana: tudo isso é cultura. Cada um podia se descobrir por meio daquilo que fazia em seu cotidiano: o pedreiro, o camponês, o cozinheiro, a dona de casa. Cada um podia se descobrir como pessoa que fazia obras complementares à situação do mundo em que se encontrava. Dessa forma, eles descobriram o valor de si mesmos como pessoas. Ou seja: "Eu também sou um criador”, "Eu também sou um recriador deste universo”. Isso gerou condições para o questionamento daquilo que Paulo Freire chamou de cultura do silêncio, resignação, ideia da impossibilidade de transformar a realidade por causa da opressão e para passar de uma consciência ingênua (as coisas são assim porque é assim mesmo) para uma consciência crítica, capaz de problematizar a realidade existente. Portanto o método freiriano visava a conscientização junto à alfabetização, como duas facetas da mesma moeda. E compreendia a conscientização não como a uma simples tomada de consciência, mas como um processo complexo de superação da esfera espontânea da percepção da realidade, que pode se realizar somente através do enraizamento dos seres humanos na própria realidade e um crescente compromisso com ela (BEISIEGEL, 2010).

Paulo Freire criou uma metodologia baseada na participação e no diálogo. Ao invés de usar frases pré-constituídas e distantes da realidade, o grupo de educadoras e educadores fez emergir do diálogo as palavras mais significativas, parte do cotidiano da comunidade e que apresentavam uma adaptabilidade fonética à aprendizagem. Paulo Freire as definirá em Pedagogia do Oprimido “palavras geradoras”. Expressões do quotidiano: povo, tijolo, milho, água, seca. Palavras que emergiram de ditos, canções, orações, festas, reuniões de trabalho, reuniões sindicais, fruto de pesquisas participativas e comunitárias. A palavra é considerada em seu sentido mais profundo, relacionado ao cotidiano, à experiência que traz, à intencionalidade que possui, às emoções que desperta. A palavra vivida passa a ser a base do processo de alfabetização, indo além da mera repetição mnemônica e abrindo-se ao diálogo: como dizia Paulo Freire, "leitura da palavra, leitura do mundo”. 
Em Angicos no final da experiência de alfabetização, que ficou conhecida como as 40 horas de Angicos (porque os alunos aprenderam a ler e escrever em 40 horas), um trabalhador se levanta e pronúncia as seguintes palavras:

Senhor presidente da República, senhor governador Aluízio Alves e todos, autoridades que estão presentes, meus professores e minhas professoras e todos os colegas.

Em outra hora, há poucos dias, ninguém não sabia ler, não sabia de letras algumas, como eu era um que não sabia; só sabia o que era um "O", que era que nem a boca da panela; o "A", que nem um ganchinho de pau. E hoje em dia, graças a Deus e os meus professores, já assino o meu nome e leio algumas coisas, graças a Deus.

Tanto, que fiquei bastante satisfeito, com o alfabetismo que faz a nós aprendermos. Eu já com a idade avançada, com 51 anos, mas graças a Deus tenho a inteligência e vou já escrevendo qualqué coisa.

Hoje mesmo, fiz uma cartinha pra o senhor presidente da República, dizendo algumas coisas.

E do mais que peço a Sua Majestade, que é a pessoa maior que nós enxerguemos no Brasil, é o presidente da República, qualqué coisa, viu. Peço que continue o curso de aula para nós todos, não tão somente no Rio Grande do Norte, como em todos os lugares por aí que tem necessidade, milhares e milhares que não sabem as primeiras letras do alfabeto.... falta alguma coisa (LYRA, C. 1996 pag.115).

O discurso foi recebido com fragorosos aplausos. Infelizmente, porém, o curso não continuou. Paulo Freire, aquele menino à sombra da mangueira, foi perseguido, junto com educadores e alunos.

\section{A disseminação e a radicalização da pedagogia freiriana no encontro com outros contextos}

O fato de ter alfabetizado 400 pessoas em 40 horas e 40 dias causou para Paulo Freire os mesmos dias de prisão. Com o golpe de estado de 2 de abril de 1964, a repressão militar no Brasil, arbitrária e extremamente violenta, usou o pretexto de uma suposta ameaça comunista. Não faltaram casos de pessoas que sofreram diversos tipos de torturas ou pagaram com a vida a própria militância política e o compromisso com a democracia. Dava-se início a página dolorosa da ditadura militar no Brasil. Nesse contexto difícil, a situação pessoal do educador Paulo Freire não era mais compatível com o novo clima político do país latinoamericano. Educadores que colaboraram com ele, como Marcos Guerra, foram presos na tentativa de eliminá-los, de fazê-los desaparecer. Alguns alunos queimaram ou esconderam seus cadernos por medo de perseguição, como se as palavras geradoras fossem verdadeiras armas. Na verdade, eram armas: 
perigosas armas do pensamento crítico. Como muitos companheiros, Paulo Freire, depois do cárcere, foi para o exílio, mas como ele mesmo testemunhou, o exílio não significará absolutamente resignação:

\begin{abstract}
"Sofrer o exílio é assumir o drama da ruptura que caracteriza a experiência de existir num contexto de empréstimo. Sofro o meu exílio ao lidar melhor com as dificuldades provocadas pela impossibilidade de voltar à minha origem. Ao resolver as contradições entre o presente que vivo num espaço em que não vivi o passado, e o futuro a ser construído num espaço incerto (FREIRE, P. 1995, pag.51).
\end{abstract}

Ocorreriam mais de 15 anos após esse depoimento para o retorno de Paulo Freire ao Brasil. Iniciou-se uma longa peregrinação que o levou do Brasil à Bolívia, onde ficou somente algumas semanas devido à forte pressão atmosférica e um outro golpe militar. Da Bolívia ao Chile - onde coordenará um plano de alfabetização integrado à reforma agrária por mais de 5 anos através do qual o país chileno conseguiu o prêmio da UNESCO por superar o drama do analfabetismo. Do Chile aos Estados Unidos onde lecionou na Universidade de Harvard e criou um grupo de pedagogia crítica, discutindo e disseminando seu pensamento em universidades norte-americanas. Dos Estados Unidos à Suíça como consultor em educação de adultos no Conselho Mundial de Igrejas em Genebra. E da Suíça para a África engajando-se em programas de alfabetização em países de língua portuguesa como Cabo Verde e Guine Bissau, que lutavam para se descolonizar do fascismo do Portugal de Salazar. Para, então, voltar ao Brasil no início dos anos 80. Neste sentido, como assinala Streck (2008), a pedagogia de Freire se configura como uma pedagogia de movimento num sentido profundamente existencial: é uma pedagogia que nasce de deslocamentos, atravessamentos, partidas, retornos, e tráficos de ideias.

Com certeza Paulo Freire não reclamava, mas projetava, como ele mesmo escrevia. Não há dúvida sobre isso. Projetar significa reinventar. Não repetir ou reproduzir. As experiências não transplantam, elas se reinventam - escreveu Paulo Freire (1977). E mais uma vez nos advertiu: "Não quero ser seguido, quero ser reinventado”. Uma das preocupações permanentes do educador Paulo Freire era não atribuir a pretensão de universalidade às próprias experiências e métodos educacionais, mesmo os de maior sucesso. Nisso reside a humildade de buscar aprender constantemente com a prática e de considerar a teoria como reflexão crítica sobre a própria prática. 
Consequentemente, a perspectiva e o desafio eram os de construir uma compreensão cada vez mais crítica do caráter político e libertador da alfabetização de adultos, das relações entre alfabetização e pós-alfabetização, do projeto global de sociedade, das relações entre educação e sistema produtivo. Além disso Paulo Freire buscou compreender a importância da educação política e, em particular para a experiência africana, a relação entre educação e sistema de produção e educação e as políticas descoloniais. Freire admirava profundamente Amílcar Cabral, líder da independência de Capo verde e Guinea Bissau, e concordava com sua afirmação de que a luta pela Independência é "Um fato cultural e um fator de cultura" (FREIRE, 1977).

Segundo Paulo Freire, a colonização utilizou a escola para manipular a realidade, inculcando na mente e na vida do colonizado uma condição de dependência do colonizador da que consegue a falsa crença de inferiridade, incapacidade, baixa autoestima. O que Paulo Freire chamou de cultura do silêncio referindo-se aos contextos rurais do Brasil. A "escola colonial" sobrepôs sua cultura dominante à cultura de um povo colonizado, sua história, suas línguas, suas expressões culturais, tradições, a imaginação. Dessa forma, criou-se uma espécie de realidade paralela. Nesse contexto a identidade e a consciência pessoal se dividem entre a cultura própria e a do colonizador. Segundo Albert Memmi (2007), um dos inspiradores do pensamento de Paulo Freire, colonizados e colonizadores são duas figuras especulares, que se reproduzem reciprocamente. Portanto para alcançar uma autêntica libertação é necessário reformular radicalmente essa relação.

Em particular, os oprimidos hospedam o opressor dentro de si, portanto a consciência de sua própria opressão é distorcida pelo fato de se encontrarem imersos na realidade dos opressores e ter o opressor como seu único modelo. Aderindo a eles, não podem adquirir autoconsciência, como pessoas, muito menos consciência da classe oprimida:

Os oprimidos, que introjetam a "sombra" dos opressores e seguem suas pautas, temem a liberdade, na medida em que esta, implicando a expulsão desta sombra, exigiria deles que "preenchessem" o "vazio"deixado pela expulsão com outro "conteúdo" - o de sua autonomia. A liberdade, que é uma conquista e não uma doação, exige uma permanente busca ... Os oprimidos, contudo, acomodados e adaptados, "imersos" na própria engrenagem da estrutura dominadora, temem a liberdade, enquanto não se sentem capazes de assumi-la. (FREIRE, 2006, p.37) 
Colonizar significa impor um sistema e anular outro. Inculcar uma cultura, mortificar a outra. Há colonizações evidentes, mas também há colonizações mais subterrâneas, menos reconhecíveis, são aquelas em que os oprimidos não sabem ou não têm plena consciência de sê-lo, porque não veem os opressores. A colonização histórica que devastou os países mais frágeis se integra à colonização do Ocidente que oprime, porque usa o capitalismo como instrumento de dominação e persuasão. A dialética escravo-senhor em Hegel, o conflito proletário-burguês em Marx se dissolve em nosso tempo em que a humanidade em um nível global se oprime não renunciando ao caráter predatório do capitalismo, mas tornando-se caçador e preda, oprimido e opressor.

Se cria um vórtice que ameaça a existência da terra, seu equilíbrio ecológico, bem-estar e vida em comunidade. Venceu o pensamento único do capitalismo, que vê cada divergência com desconfiança e tenta explorar todas as ferramentas possíveis, mídia de massa, novas tecnologias, redes sociais, a própria educação, para reprimir por meio de dispositivos de vigilância. Precisamente para não resignar, para projetar, é preciso reler autores como Paulo Freire e compreender a sua prática de libertação à luz do nosso tempo. Devemos lutar para que o mundo da educação não se alinhe com o pensamento único de competitividade, excelência, produtividade, sucesso, mas busque continuamente espaços de diálogo, debate, escuta, solidariedade. O exílio de Paulo Freire se explica não pelo delirante relatório do julgamento militar que queria nos fazer crer que ele era um comunista soviético, inimigo da pátria, ou que as palavras geradoras eram como armas de destruição em massa, mas com um projeto que vem de longe e quer reduzir a humanidade a um só pensamento.

\section{Aprender com os outros: uma teoria que surge da reflexão sobre a prática}

... Um dia... falei longamente... baseando-me num excelente estudo de Piaget sobre o código moral da criança... Ao terminar, um homem jovem ainda, de uns 40 anos, mas já gasto, pediu a palavra e me deu a mais clara e contundente lição que já recebi em minha vida de educador

... "Acabamos de escutar", começou ele, "umas palavras bonitas do dr. Paulo Freire. Palavras bonitas mesmo. Bem-ditas. Umas até simples, que a gente entende fácil. Outras, mais complicadas, mas deu para entender as coisas mais importantes que elas todas juntas dizem... 
Agora, eu queria dizer umas coisas ao doutor que acho que os meus companheiros concordam... Me fitou manso... e perguntou: "dr. Paulo, o senhor sabe onde a gente mora? O senhor já esteve na casa de um de nós?" Começou então a descrever a geografia precária de suas casas, a escassez de cômodos, os limites ínfimos dos espaços em que os corpos se acotovelam. Falou da falta de recursos para as mais mínimas necessidades. Falou do cansaço do corpo, da impossibilidade dos sonhos com um amanhã melhor. Da proibição, que lhes era imposta, de ser felizes. De ter esperança.

"Pois bem, doutor, sua casa deve de ser uma casa solta no terreno, que a gente chama de 'oitão livre'. Deve de ter um quarto só para o senhor e sua mulher. Outro quarto grande, é para três meninas. Tem outro tipo de doutor que tem um quarto para cada filho e filha. Mas o senhor não é desse tipo, não. Tem outro quarto para os dois meninos. Banheiro com água quente. Cozinha com a 'linha Arno'... Agora, veja, doutor, a diferença. $\mathrm{O}$ senhor chega em casa cansado. A cabeça até que pode doer no trabalho que o senhor faz. Pensar, escrever, ler, falar esses tipos de fala que o senhor fez agora. Isso tudo cansa também. Mas - continuou - uma coisa é chegar em casa, mesmo cansado, e encontrar as crianças tomadas banho, vestidinhas, limpas, bem comidas, sem fome, e a outra é encontrar os meninos sujos, com fome, gritando, fazendo barulho. $\mathrm{E}$ a gente tendo que acordar às quatros da manhã do outro dia para começar tudo de novo, na dor, na tristeza, na falta de esperança. Se a gente bate nos filhos e até sai dos limites, não é porque a gente não ame eles não. É porque a dureza da vida não deixa muito para escolher (FREIRE, 1992, pp. 24-27).

Paulo Freire narra esse episódio. Ele sempre se lembra disso em seu trabalho e explica que com aquele trabalhador ele aprendeu o que é o conhecimento de classe. Ele compreendeu com o tempo que a educadora, o educador não deve tanto falar para, mas falar com. E isso implica respeito pelo conhecimento construído na experiência. Paulo Freire entendeu através da humilhação que aquele trabalhador sofria que - apesar de alguns anos de experiência como educador - ele sempre partia de seu mundo como se devesse ser o único elemento para dar à luz aos seus alunos, "Foi como se minha palavra, meu tema, minha leitura do mundo tivesse o poder de guiá-los" (FREIRE, 1992 p. 27) - admitiu Paulo Freire. Com o tempo foi lembrando da sabedoria daquela crítica áspera recebida como se fosse a capa de um livro sempre deixado aberto na busca de suas experiências. Com humildade, ele transformou a frustração de uma lição recebida pela veemência de uma crítica pública em sábio conselho. Um dos ensinamentos que ele, então, nos passou e que ainda nos fazem refletir é o de se colocar em uma condição de humilde aprendizagem não só dos livros e da teoria, mas também e sobretudo da prática. Aprender da prática à teoria e da teoria à prática, o que significa uma disposição aberta e permanente para o diálogo. Inspirado também por essa experiência, pela dura lição recebida pelo 
trabalhador, Paulo Freire foi assumindo uma postura crítica ao longo de sua vida com relação àquela abordagem didática que prevê um sujeito ativo, o professor, e mais os objetos receptores, os alunos.

Freire tenderá continuamente a superar uma abordagem relacional adaptativa e conformadora, que ele definirá em sua obra como sendo "educação bancária”. Na Educação Bancária, os conteúdos perdem a vitalidade que assumiriam através do debate e do diálogo e se apresentam como meras noções a serem assimiladas, transformando-se em noções arquivistas que se somam e se depositam. Justamente por isso, Paulo Freire define essa prática também como educação depositária. Um modelo de educação em que o professor tem a primeira e a última palavra e os alunos só podem aceitar passivamente o que o professor diz, talvez repetindo de forma mnemônica. A Educação Bancária propõe um esquema técnico ainda muito presente em nossas escolas e universidades. $\mathrm{O}$ conhecimento é estático na transmissividade, ao invés de evoluir no diálogo. Como o próprio Paulo Freire afirma, na concepção bancária da educação, o conhecimento é um dom concedido a quem se considera seu dono e que acredita que nada sabe. Projetar ignorância absoluta sobre os outros é uma característica de uma ideologia de opressão, disse Paulo Freire.

Paulo Freire contrapõe a Educação Bancária à Educação Crítica. A educação crítica centra-se na criatividade, na dialética entre teoria e prática, ação e reflexão, respondendo à necessidade humana de intervir na realidade não só interpretando e compreendendo-a, mas também fazendo da própria interpretação um motivo de transformação, tendendo a um saber que não é um conhecimento pré-embalado ou pré-estabelecido, mas se constrói através do diálogo.

A premissa da educação crítica está no diálogo. O diálogo surge de uma condição de estar consciente de não ser imutável, mas que sabe de ser incompleto. Precisamente da incompletude do ser humano surge a necessidade existencial de diálogo, à qual a educação deve dar uma resposta. A relatividade do aprender, do saber, do ensinar implica uma condição de humildade do professor que, na visão de Paulo Freire, não deve e não pode ser colocado na falsa presunção de transmitir conhecimentos a grupos de ignorantes, mas deve colocar-se numa dimensão comunicativa respeitando e valorizando o saber de quem encontra. 


\section{Freire hoje: os movimentos sociais construtores do inédito possível}

Em uma declaração pública, o atual Presidente do Brasil Jair Bolsonaro, excitado e aclamado por pouca, mas exaltada gente, insulta a memória de Paulo Freire, chamando-o de "energúmeno" e - obviamente em um sentido depreciativo - de "ídolo de esquerda". O fato de chamar "energúmeno" literalmente fanático, obcecado, obcecado- um educador humilde e profundamente sensível como Paulo Freire enraíza-se eficazmente nessa grande escala de setores - digamos não exatamente moderados - que nos levam a um mundo de cenários da inquisição. As expressões maledicentes do ex-militar tendem a buscar a todo custo o bode expiatório para o setor público de educação e deixam espaço para a mais inescrupulosa iniciativa privada.

Por outro lado, essa perseguição raivosa contra Paulo Freire, na verdade, sinaliza a força de seu pensamento. Se no século XX as armas para silenciar o autor da Pedagogia do Oprimido foram as do exílio e da força militar, em nossos anos dominam as armas da fake news, da calúnia, do tráfico de uma falsa identidade.

Mas por que Paulo Freire assusta tanto a extrema direita?

A esperança em Paulo Freire não é apenas uma atitude romântica, mas a raiz concreta de um método baseado na denúncia das condições de opressão e na consequente organização política para superá-las, o que provoca interpretações de sentido, leituras de mundo, pontos de vista até aquele momento inéditos. Esse é o sentido da educação em Paulo Freire, que não teria sido exilado e perseguido se o seu método de alfabetização, inserido em um sistema político-educacional mais amplo, não tivesse sido realmente gerador de transformações na história. A esperança, como necessidade existencial, deve estar ancorada na prática: é essa prática que encontra raiz histórica em organizações políticas como o Movimento dos Trabalhadores Rurais Sem Terra, por exemplo, e outros movimentos populares rurais e urbanos, sindicatos autônomos, comunidades de base, movimentos de mulheres, de camponeses, trabalhadoras e trabalhadores, que, por serem sujeitos de um processo político de educação popular, constroem o que ainda não existe, mas pode-se criar: o inédito possível. 
O inédito possível se gera e cresce na construção de relações que pretendem superar a exploração de uma classe, de um gênero, de um sujeito sobre o outro.

O sentido político da educação ou, como ele mesmo dizia, a educação como ato político, está profundamente enraizada nos movimentos e organizações de base, porque tem um sentido poético profundo. O que enfurece a ordem estabelecida sobre sistemas de opressão e exclusão é a poesia da educação que é ver a realidade não só como ela é, através de estudo, rigor e análise histórica, mas como ela poderia ser ou não ser, como poderia devir. O que move o ser em devir é a capacidade criativa: "O mundo não é o mundo está sendo".

\section{Referências bibliográficas}

BEISIEGEL, C. R. Paulo Freire. Recife: Fundação Joaquim Nabuco-Editora Massangana, 2010.

FREIRE, Paulo. Cartas à Guiné-Bissau. Registros de uma experiência em processo. Rio de Janeiro: Paz e terra, 1977.

FREIRE, P. Pedagogia da esperança. Um reencontro com a pedagogia do oprimido. São Paulo: Paz e Terra, 1992.

FREIRE, P., À sombra dessa mangueira, São Paulo: Olho D’Água, 1995.

FREIRE, P. A Pedagogia do Oprimido, São Paulo: Paz e Terra, 2006,

LYRA, Carlos. As quarentas horas de Angicos. São Paulo: Cortez, 1996

MEMMI, A. Retrato do colonizado precedido de retrato do

colonizador. Rio de Janeiro: Civilização brasileira, 2007.

STRECK, Danilo R. Uma pedagogia em movimento: os movimentos sociais na obra de Paulo Freire. In: MAFRA, Jason et al. Globalização, Educação e Movimentos Sociais: 40 anos da Pedagogia do Oprimido. São Paulo: Instituto Paulo Freire e Esfera, 2009, pp.63-72.

VITTORIA, P. Narrando Paulo Freire. Para uma pedagogia do diálogo. Rio de Janeiro: UFRJ, 2011.

Vittoria, P. Angicos, uma experiencia política. Entrevista com Marcos Guerra

https://www.youtube.com/watch?v=Y_xt6ZxW7EM\&t=1743s 
Vittoria, P. Leggere il mondo con Paulo Freire. Podcast per Il Manifesto https://ilmanifesto.it/paulo-freire-un-alfabeto-di-speranza/

\section{Sobre os autores}

Mariateresa Muraca: Possui graduação em Scienze della Professionalità Educativa - Università degli Studi di Perugia (2007), mestrado em Educazione permanente - Università di Bologna (2010), doutorado em Interdisciplinar em Ciências Humanas pela Universidade Federal de Santa Catarina (2015) e em Scienze dell'Educazione e della Formazione Continua - Università di Verona (2015). Atua principalmente nos seguintes temas: educação popular, movimentos sociais, educação dos adultos, pensamento decolonial latinoamericano, teorias feministas, metodologias de pesquisa críticas e dialógicas. ORCID: https://orcid.org/oooo-0002-3250-0988

Paolo Vittoria: Desde 2017 Professor de Pedagogia da Università Federico II di Napoli - Itália. Departamento de Estudos Humanisticos. De 2011 até 2017 Professor de Filosofia da Educação na Faculdade de Educação e no Departamento de Fundamentos da Educação. Licenciado em Letras - Università degli Studi di Napoli Federico II UNINA (2002), Doutorado em Pedagogia da Formação Università degli Studi di Napoli Federico II - UNINA - (2008); Pós-Doutorado em Políticas da Educação - Universidade Federal Fluminense - UFF - Rio de Janeiro (2010) apoio bolsa FAPERJ. Adjunct Professor da Catedra Interdisciplinar UNESCO em Desenvolvimento Humano e Cultura da Paz. Professor Visitante na Universitatia Lucian Blaga de Sibiu (Romênia) "Departamentul pentru Pregatirea Personalului Didactic". Anglia Ruskin University (Chelmsford - London), Universidad de Santiago del Chile. ORCID: https://orcid.org/oooo-0oo1-6978-3523

\section{Tramitação:}

Recebido em:05/11/2021

Aprovado em: 20/12/2021 